\title{
Predicting the strength and maturity of hardening concrete
}

\author{
Irina Belykh, Viktor Sopov*, Larisa Butska, Lidiya Pershina, and Olga Makarenko \\ Kharkiv National University of Civil Engineering and Architecture, Sumskast. 40, 61002 Kharkiv, \\ Ukraine
}

\begin{abstract}
When predicting the growth of strength and maturity of hardening concrete, the role of the temperature factorshould be taken into account. Taking into account the temperature factor requires at the initial stage of hardening of concrete low positive temperatures and low speed of heating concrete. The level of maximum heating of concrete will depend not only on the exothermy of the cement, but also on the amplitude of the fluctuations in the ambient temperature. The contribution to the cracking of concrete of various types of cements from the point of view of heat release during their hydration is analyzed. The existing models for predicting the character of the set of strength and maturity of concrete on the basis of data on heat dissipation during hydration of cement in concrete structures are analyzed. It is shown that laboratory tests are insufficient to evaluate the nature of heat generation. To effectively predict the physical and mechanical properties, it is necessary to conduct temperature-time monitoring during the concrete hardening in the design to take into account the influence of external factors.
\end{abstract}

\section{Introduction}

One of the main challenges of monolithic concreting is the problem of ensuring the temperature crack resistance of concrete. The formation of temperature cracks is associated with heating and cooling of concrete when it hardens in the structure. Heating is caused by heat release in concrete due to exothermic reactions of hydration of cement during its interaction with water. Since heat cannot be transferred instantaneously, the temperature gradients will be observed in the volume of the laid concrete, which will lead to the development of significant tensile stresses at the outer edges of the concrete massif. Also, crack formation can be caused by the effect of fluctuating outdoor air temperatures and the heat exchange conditions of the structural elements with the environment.

Temperature control in a concrete structure is one of the main measures to ensure the fracture toughness of concrete [1-4].

When predicting the growth of strength and maturity of hardening concrete, it is necessary to take into account the role of the temperature factor.

Taking into account the temperature factor requires low positive temperatures and low speed of heating concreteat the initial stage of hardening of concrete. In this case, the level

*Corresponding author: vsopov@ukr.net 
of maximum heating of concrete will depend not only on the exothermy of the cement, but also on the amplitude of the variations in the ambient temperature.

The prevention of crack formation from various types of temperature influences, caused by the peculiarities of external and internal heat exchange in the structures at the stage of their erection, in order to ensure high consumer properties, today puts in monolithic construction an important and urgent task that predetermines the purpose of this work and the direction of research.

\section{Materials and methods of research}

Various types of cements were investigated in accordance with the classification of DSTU B.V 2.7-46: 2010 [5], whose compositions are given in Table 1.

Table 1. Types and mineral compositions of cements.

\begin{tabular}{|l|l|l|l|l|l|l|l|}
\hline Type of cement & \multicolumn{3}{|l|}{ Mineral content, \% } & $\begin{array}{l}\text { Specific } \\
\text { surface, } \\
\mathrm{cm}^{2} / \mathrm{g}\end{array}$ & $\begin{array}{l}\text { Activity, } \\
\mathrm{MPa}\end{array}$ & $\begin{array}{l}\text { Total heat } \\
\text { evolution for 7 } \\
\text { days, } \mathrm{kJ} / \mathrm{kg}\end{array}$ \\
\hline I (CEM I) & 57 & 18 & 10 & 8 & 3650 & 42.3 & \\
\hline II (CEM II/B-S) & 56 & 19 & 7 & 10 & 3730 & 38.6 & \\
\hline III (CEM Ill/A) & 55 & 17 & 10 & 9 & 3530 & 37.3 & \\
\hline IV (CEM IV/A) & 54 & 22 & 5 & 11 & 3820 & 38.2 & \\
\hline
\end{tabular}

To estimate the magnitude of heat release during hydration of cements and concretes, the pseudo-adiabatic calorimetry method was used [6-8].

Determination of compressive strength of concrete samples $10 \times 10 \times 10 \mathrm{~cm}$ was carried out in accordance with DSTU B.V.2.7-214: 2009 [9].

\section{Main part}

It is known that with increasing temperature the rate of cement hydration processes in concrete increases in accordance with the Arrhenius equation. This contributes to a faster growth of concrete strength. Varying the conditions of hardening, relationship between the strength of the concrete and the temperature of its hardeningcan be established.

However, the exothermic nature of cement hydration in concrete contributes to an additional contribution to the temperature regime of hardening. The presence of resistance to heat transfer leads to the formation of an uneven temperature distribution in the volume of concrete [10-11]. As a consequence, there are temperature gradients between different parts of the structure, which contributes to the occurrence of cracks. Thus, cracking in hardening concrete can be caused by both hardening conditions and the nature of heat release.

Analysis of the literature sources [12-14] allowed to determine the correlation between the temperature gradient (temperature difference at the surface and in the core of the concrete structure) and the strength of the concrete (Fig. 1). 


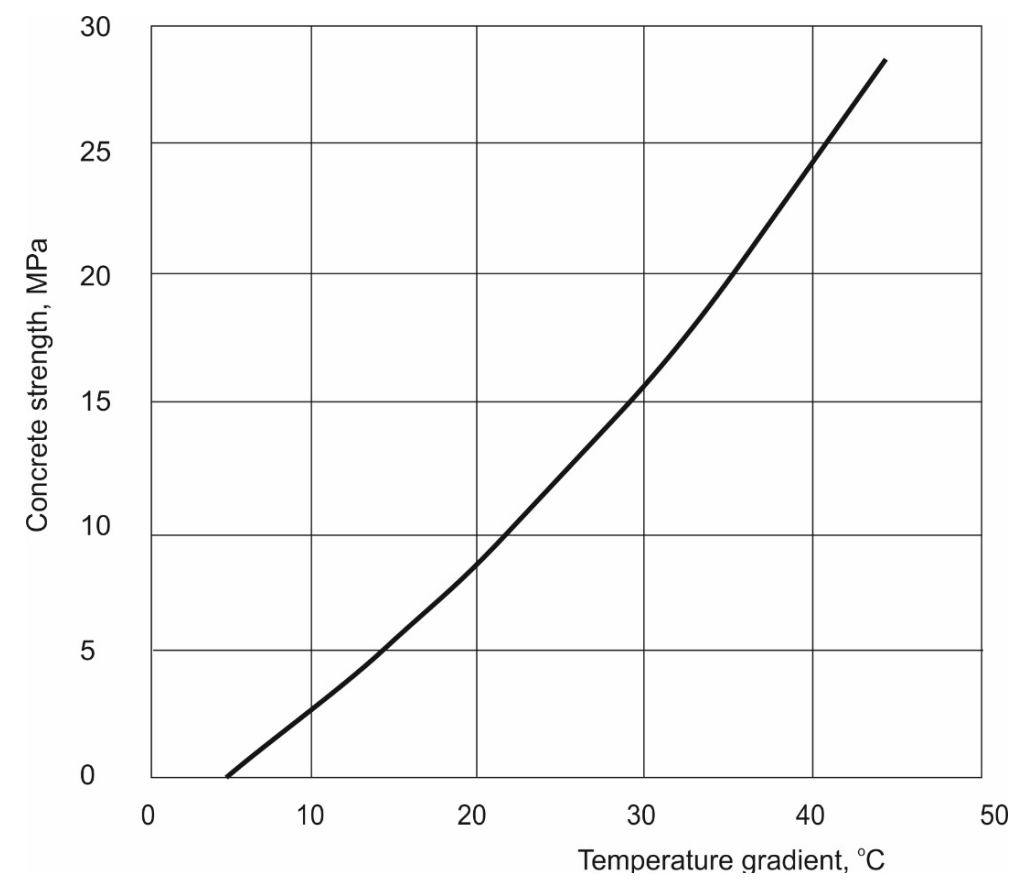

Fig. 1. Dependence of the compressive strength of concrete on the magnitude of the temperature gradient.

Depending on the conditions of hardening, the time of the year, the massiveness of the concrete structure, the time of aging in the formwork, it is possible to determine the optimum compositions of concrete of specified properties by the value of heat evolution.

When predicting the growth of strength and maturity of hardening concrete, it is necessary to take into account the effect of the temperature factor on:

1) magnitude of the temperature gradient;

2) magnitude of the temperature stresses between different parts of the structure.

Calorimetric analysis of hardening cement pastes presented in Table 1 is shown in Fig. 2.

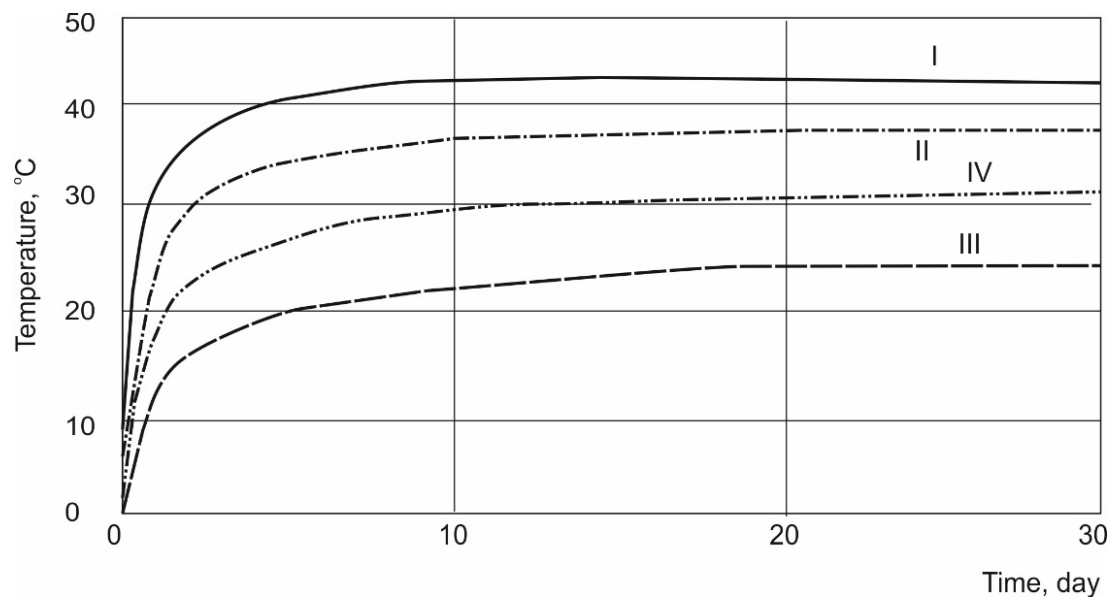

Fig. 2. Temperature value of hardening cement pastes: I, II, III, IV - types of cements according to Table 1. 
The change in the temperature of hardening concrete based on the cement under study is shown in Fig. 3.

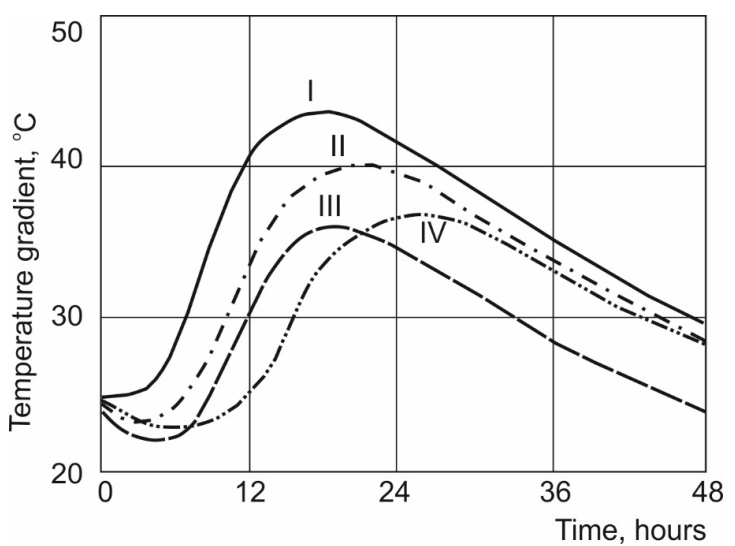

Fig. 3. Change in temperature gradient during hardening of concrete: I, II, III, IV - types of cements according to Table 1 .

As can be seen from Fig. 3, the magnitude of the temperature gradient and the time of the onset of the maximum depend on the mineral composition of the cements, the type and amount of mineral additives in their composition. Temperature measurements were carried out in concrete samples measuring $1.0 \times 1.0 \times 1.0 \mathrm{~m}$ on the surface of the concrete block and in the center. An increase in the block size by a factor of 2 leads to an increase in the temperature gradient by a factor of 1.2.

The magnitude of the gradient is also affected by fluctuations in the ambient temperature, the presence and force of the wind, the form of the formwork and many other factors that can not be cited within the framework of this article.

Accounting for all factors is very difficult due to not always predictable weather changes. Therefore, to estimate the maturity of concrete $M(\tau, t)$, the averaged approach is used[15-16]. In this paper we used the following relation:

$$
M(\tau, t)=\sum\left(t_{r}-t_{0}\right) \Delta \tau,
$$

Where $t_{\tau}$ is the temperature of the concrete at time $\tau, \mathrm{t}_{0}$ is the temperature of the concrete mixture at the time of laying; $\Delta \tau$ is the curing time.

The maturity value of concrete makes it possible to estimate the average strength of concrete at a given time $\mathrm{R}_{\tau}$ :

$$
R_{\tau}=R_{28} \exp ^{-\left[\frac{\tau}{M}\right]^{a}}
$$

Where $R_{28}$ - given strength of concrete; $\alpha=\frac{t_{\tau}-t_{0}}{t_{n}-t_{0}} ; t_{n}=25^{\circ} \mathrm{C}$.

Dependence of strength of concrete class B30 on maturity for the types of cement studied is shown in Fig. 4. 


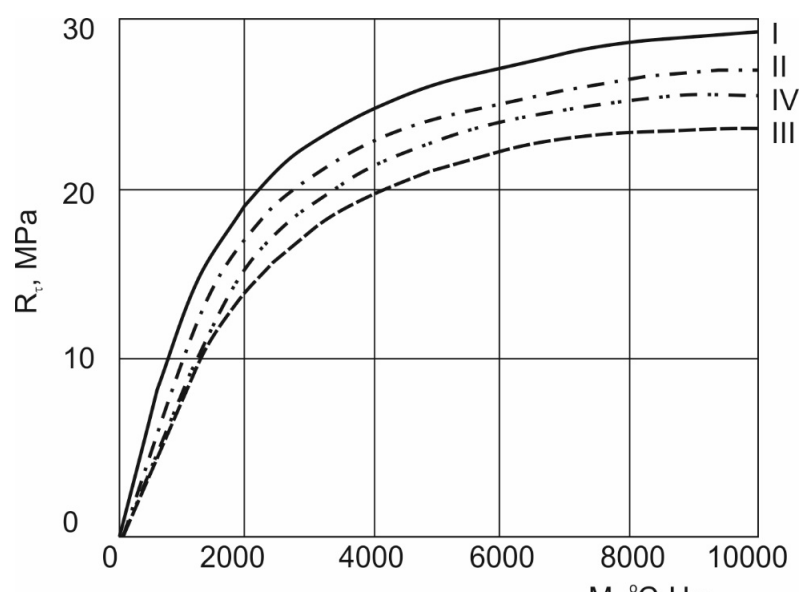

Fig. 4. Dependence of strength of concrete from maturity for the types of cement studied.

Thus, without rigidity tests, it is possible to obtain sufficiently accurate strength values of concrete at any time of hardening, based on temperature monitoring data.

\section{Conclusion}

The increase in temperature as a result of the release of heat of hydration, together with shrinkage deformations, is one of the possible load-independent causes of the appearance of cracks in young concrete.

The conducted studies enable establishinga correlation between the composition of cement and the nature of the strength set of concrete on its basis, based on the calorimetric determination of the temperature change during cement hydration in concrete.

The obtained dependences of strength of concrete from its maturity make it possible to determine the time of removal of the formwork from a concrete construction using different types of cements.

Observing the temperature changes of concrete in a certain area of the structure, you can:

- rather accurately determine the current strength of concrete in this zone;

- to know that the concrete is not frozen and not overheated;

- to control and observe the temperature parameters of the rates of heating-cooling of concrete normalized for monolithic structures;

- evaluate the air-concrete temperature gradient and correlate it with the allowed normalized values when the formwork is removed.

\section{References}

1. G. Wischers, Beton,14, H. 1 und H. 2 (1964)

2. R. Springenschmid, P. Nischer, Beton- und Stahlbetonbau, 68, 9 (1973)

3. G. Thielen, H. Grube, Beton-und Stahlbetonbau, 85, 6(1990)

4. Prediction of creep, shrinkage, and temperature effects in concrete structures, ACI 209R-92, Report of Committee 209, Manual of Concrete Practice, American Concrete Institute,Farmington Hills, MI (Reapproved, 1997) 
5. DSTU B.V 2.7-46: 2010.Cements for general construction purposes. Technical specifications (State standard of Ukraine, Kyiv, 2010)

6. I.M. Belykh, V.P. Sopov, Building materials and products,1-2 (97)(2018)

7. M. Azenha, R. Faria, D. Ferreira, Cement and Concrete Composites. Elsevier: Banthia N., 31 (2009)

8. I.M. Belykh, V.P. Sopov, L. Butskaya, P. Dolya, Motrol. Commission of motorization and energetics in agriculture, 18, 6(2016)

9. DSTU B.V.2.7-214: 2009. Concretes. Methods of determining the validity for control models (State standard of Ukraine, Kyiv, 2010)

10. Y. Ballim, Cement \& Concrete Composites, 26 (2004)

11. S.W. Phillips, W. Aquino, W.M. Chirdon, Journal of Engineering Mechanics, 133 (2007)

12. W. Hintzen, Schriftenreihe der Zementindustrie, 59 (1998)

13. M.L. Goral, J. Am. Conc. Inst., 53(2), 215 (1956)

14. F.K. Chin, J. Am. Conc. Inst., 68(3), 196 (1971)

15. J.M. Plowman, Mag. Concr. Res., 8(22), 13 (1956)

16. V.M. Malhotra, Maturity Concepts and the Estimation of Concrete Strength - a Review (Department of Energy, Mines and Resources, Mines Branch, Ottawa, IC277, November 1971) 